\title{
Carbon dioxide will be harder
}

Last week's successful review conference of the Montreal Protocol on ozone would have served an even better purpose by spending more time on verification and compliance.

LONDON had hardly said goodbye to last week's gathering of the parties to the Montreal Protocol on ozone than it was filled with the delegations of the members of the North Atlantic Treaty Organizations, who will be discussing (among other things) the prospects for further arms control measures in Europe. There seems little doubt that the people at the earlier gathering are a more trusting lot than those at the second. What does either group have to learn from the other?

For decades, it has been taken for granted that there can be no arms control without verification. The assumption has always been that the stakes are too high to take the other fellow's word on trust. This is one of the reasons (there were several others) why, in 1979, the then US President Jimmy Carter did not send the SALT II treaty (on strategic arms) to the US Senate for ratification: as negotiated, it allowed only for 'national means' of verification, which was a euphemism for the use of surveillance satellites. By contrast, the treaty on nuclear missiles of intermediate range, signed at the end of 1988 , and the START treaty now being negotiated, include provisions for the direct inspection of disarmed missiles, sometimes on unprovoked demand.

The Montreal Protocol does not yet have teeth like that. Even in its newly tightened form (see page 6), the convention is not especially specific about the the baseline data, for 1986 and 1989, against which future reductions of chlorofluorocarbons (CFCs), and variants on that theme, are to be assessed. The secretariat requires of the governments that are members of the convention that they supply details of production and consumption of the various materials interacting with ozone in the stratosphere. And where will those data come from? The only possible sources are the companies that manufacture them, and which must be supposed to have a vested interest in inflating their first estimates so as, later, to be less hurt by the proportionate reductions to which they have agreed.

At least on past form, the arms controllers would not so easily have taken what their fellow signatories had to say about their own dispositions as synonymous with the truth. In the absence of 'national means of verification', there would have been calls for lists of the manufacturing plants at which offending operations were being carried on, as well as for opportunities for inspecting them. For what it is worth, the signatories of the Montreal Protocol might reasonably have bound themselves to provide a list of the plants manufacturing CFCs and the other substances now controlled, if only so as to be better able to tell what to make of newly constructed plants if they should make their appearance in the years ahead.

It is also surprising that the Montreal Protocol is as innocent as it seems of formal arrangements for the systematic monitoring of the now-controlled materials. The ostensible objective of the enterprise is to regulate the concentration of these chemicals in the stratosphere, for which purpose the tropospheric concentration is a legitimate proxy. But the measurements by which the supposed increasing concentration of, for example, CFCs has been verified have mostly been carried out with air samples collected from oceanic islands.

That makes sense if the objective is to detect trends unencumbered by locally generated noise, the nearness of a chemical plant for example. Now that the convention has been made more stringent and its scope extended, its members cannot be expected to continue to rely on whatever measurements of this kind independent investigators choose to carry out, but it is plainly of more than passing interest to them to know something about sources of regional or even local noise that may betoken the presence of unsuspected chemical factories.

These issues have been given close attention over the years in negotiations to control the manufacture of chemical weapons, mostly at Geneva (in the building in which the United Nations Environmental Programme has its European office). Not so long ago, the Finnish authorities explored the use of civil aircraft equipped with air samplers and gas chromatography as a means of telling what kinds of chemical plants lie beneath civil airline routes. Fitting the exhaust stacks of all chemical factories with sealed automatic samplers would be more effective, but would encounter the objection raised, during the test-ban negotiations in 1978 , that remotely operated seismometers would provide much more extensive data than were required for the working of the treaty. Even in the cause of the Montreal Protocol, not every chemical manufacturer would welcome others knowing what flows up his chimney stacks.

Yet another lacuna in the new arrangements is financial, and concerns the procedure for recompensing developing countries for their willingness not to make CFCs, but only the substitutes for them, and to lag no more than ten years behind the rest in full compliance. It is, of course, remarkable that so many rich countries have agreed to contribute to what is called the multilateral fund to compensate developing countries for their self-denial. But it will be a headache for the lawyers and the accountants. The preamble to last week's conference document records the need to avoid "double-counting". But only trusting folk like the ozone people would have let things get this far without calling in teams of lawyers to draft their resolutions.

That is as it should be. It would have been absurd to have invested the ozone negotiation with all the niceties of the arguments there have been in the avoidance of nuclear war. That does not imply that the ozone problem is not serious, but that it is a less serious problem than the threat of nuclear war. And, as the signatories of the Montreal Protocol openly confess, the last thing on their agenda was to frighten off non-signatories by too elaborate a system of control. Fair play, the strategy has worked. It is a victory that China and India may now join.

So why rehearse the gaps in the convention that will send the world's arms controllers into shivers? Because the convention is more than a means of reducing the incidence of skin cancer, it is a model for the convention there will soon have to be on the control of the emission of greenhouse gases (among which the CFCs are incidentally important in their own right). And there the stakes will be much higher, perhaps even comparable with the threat of nuclear war. People will be less willing than over ozone to trust others to tell the truth, from the fear that they may be lying.

That is why a few arms controllers might usefully get together, in the wake of last week's successful conference, to advise the ozone people on the ways in which their protocol might have been made not just a declaration of good intentions, but watertight as well. The exercise would of course be unnecessary and thus academic, but a version of it will be needed when work begins on carbon dioxide.

John Maddox 